\title{
FORAMINIFERA BENTIK PADA TERUMBU KARANG PULAU BUNAKEN
}

\author{
(Benthic Foraminifera in Coral Reefs of Bunaken Island)
}

\section{Renaldi Kalalo ${ }^{1^{\star}}$, Jane M. Mamuaja ${ }^{1}$, Hermanto W.K Manengkey ${ }^{1}$, Janny D. Kusen ${ }^{1}$, Rignolda Djamaluddin ${ }^{1}$, Rose Mantiri²}

1. Program Studi Ilmu Kelautan Fakultas Perikanan dan IImu Kelautan, Universitas Sam Ratulangi, Manado.

2. Program Studi Manajemen Sumberdaya Perairaan Fakultas Perikanan dan IImu Kelautan, Universitas Sam Ratulangi, Manado.

*e-mail : renaldikalalo2@gmail.com

\section{ABSTRACT}

Study of benthic foraminifera on the coral reefs of Bunaken Island, North Sulawesi Province, was carried out with the aim of providing information regarding the description, distribution and FoRAM Index values on the coral reef environment of Bunaken Island. Sediment sampling in the field was carried out at 5 stations around the island, each area has been plotted on the map, with 3 repetitions and using a SCUBA tool at a depth of 3-8 meters. From observations of sediment surface samples at 15 points in 5 stations spread over Bunaken Island, 5,770 benthic foraminifera specimens have been identified. 81 species from 26 genera of foraminifera were identified and they were then grouped into functional groups to obtain the FoRAM Index. The Index were ranged from 7.18 to 10.5. This indicates that the environment of the coral reef waters around the island is still in good condition.

Keywords : Benthic Foraminifera, Coral Reef Ecosystem, Bunaken Island.

\section{ABSTRAK}

Studi foraminifera bentik pada terumbu karang Pulau Bunaken Provinsi Sulawesi Utara dilakukan dengan tujuan untuk menyediakan informasi menyangkut deskripsi, peta sebaran dan nilai FoRAM Index pada lingkungan terumbu karang Pulau Bunaken. Kegiatan pengambilan sampel sedimen di lapangan dilakukan pada 5 stasiun di perairan Pulau Bunaken yang masing-masing areanya telah diplot dalam peta, dengan 3 kali pengulangan dan menggunakan alat SCUBA pada kedalaman 3-8 meter. Dari hasil pengamatan terhadap sampel sedimen permukaan dasar perairan pada 15 titik dalam 5 stasiun tersebar di Pulau Bunaken telah teridentifikasi sebanyak 5.770 spesimen foraminifera bentik. Hasil identifikasi foraminifera tersebut diperoleh 81 spesies foraminifera bentik yang termasuk dalam 26 genus. Spesies-spesies ini kemudian dikelompokkan ke dalam kelompok fungsional untuk mendapatkan FoRAM Index, dan diperoleh kisaran 7,18-10,5. Nilai ini mengindikasikan bahwa lingkungan perairan terumbu karang di sekitar pulau tersebut ada dalam keadaan masih baik dan sehat.

Kata Kunci : Foraminifera Bentik, Ekosistem Terumbu Karang, Pulau Bunaken. 
PENDAHULUAN

Wilayah pesisir dan laut Indonesia dikenal sebagai negara dengan kekayaan dan keanekaragaman hayati laut terbesar di dunia dengan ekosistem pesisir seperti terumbu karang, mangrove dan padang lamun.

Ekosistem terumbu karang merupakan salah satu ekosistem pesisir dengan biodiversitas yang tinggi. Keunikan ekosistem serta keragaman organismenya menjadikan ekosistem terumbu karang memiliki nilai ekonomi, ekologi, bahkan sosial yang tinggi (Toruan, 2011).

Taman Nasional Bunaken (TNB) merupakan kawasan konservasi berbasis lautan yang dikelola oleh pemerintah dan ditetapkan berdasarkan SK. Menteri Kehutanan No. 730/Kpts-II/1991 dengan luas $89.065 \mathrm{Ha}$. Adapun wilayah TNB meliputi kawasan pulau-pulau yakni Pulau Bunaken, P. Manado Tua, P. Siladen, P. Mantehage, dan P. Nain, serta Pesisir Tongkaina, Tiwoho, Arakan-Wawontulap (Setiawan, 2013).

Foraminifera bentik adalah komponen meiobentik dari komunitas dasar perairan yang memiliki peran sebagai produsen kalsium karbonat $\left(\mathrm{CaCO}_{3}\right)$ dalam sedimen di hampir seluruh dasar laut di dunia (Hallock, 1974 dalam Rositasari, 2011). $\mathrm{CaCO}_{3}$ merupakan salah satu elemen pembentuk terumbu karang, sehingga foraminifera bentik dapat dijadikan sebagai bioindikator perairan terumbu karang. Foraminifera besar terutama jenis bentik merupakan bioindikator yang sangat potensial untuk mengetahui berbagai perubahan lingkungan, karena sifatnya sangat sensitif terhadap berbagai perubahan lingkungan. Sebagian besar pantai dan sedimen pada terumbu misalnya di Great Barrier Reef sangat didominasi oleh organisme ini, sehingga foraminifera bentik sangat penting dalam pembentukan sedimen lingkungan koral (Nobes dan Uthicke, 2008).
Foraminifera bentik selama ini telah dijadikan sebagai bagian dari pemantauan lingkungan perairan ekosistem terumbu karang di mancanegara. Penggunaan foraminifera sebagai indikator lingkungan terumbu karang di Indonesia telah diterapkan oleh Natsir (2010), Dewi dkk., (2010), Dewi dkk., (2012), Toruan (2011), Aulia dkk., (2012), Gustiani dan llahude (2012) serta Paringgi $d k k$., (2018).

\section{METODE PENELITIAN}

Penelitian foraminifera ini menggunakan metode sederhana melalui pendekatan foraminifera bentik dalam sampel sedimen di sekitar terumbu karang. Pengambilan sampel sedimen di perairan Pulau Bunaken dilakukan pada area terumbu karang dengan menggunakan sekop kecil, yang diambil pada permukaan dasar perairan dengan cara dikeruk pada ketebalan maksimal $2 \mathrm{~cm}$. Pengambilan sampel dilakukan pada 5 stasiun dengan 3 kali ulangan pada kedalaman 3-8 meter dengan bantuan peralatan SCUBA.

\section{Lokasi Penelitian}

Penelitian ini dilakukan pada perairan Pulau Bunaken, Provinsi Sulawesi Utara, yang merupakan kawasan Taman Nasional Bunaken, kegiatan pengambilan sampel sedimen di lapangan dilakukan pada 5 stasiun di perairan Pulau Bunaken yaitu Lekuan, Bunaken Timur, Sachiko, Tengah, dan Fukui yang masing-masing areanya telah diplot dalam peta, dan untuk penentuan stasiun dilihat berdasarkan area terumbu karang dan daerah penyelaman. Lokasi tersebut sebagaimana terlihat pada gambar 1 berikut ini : 


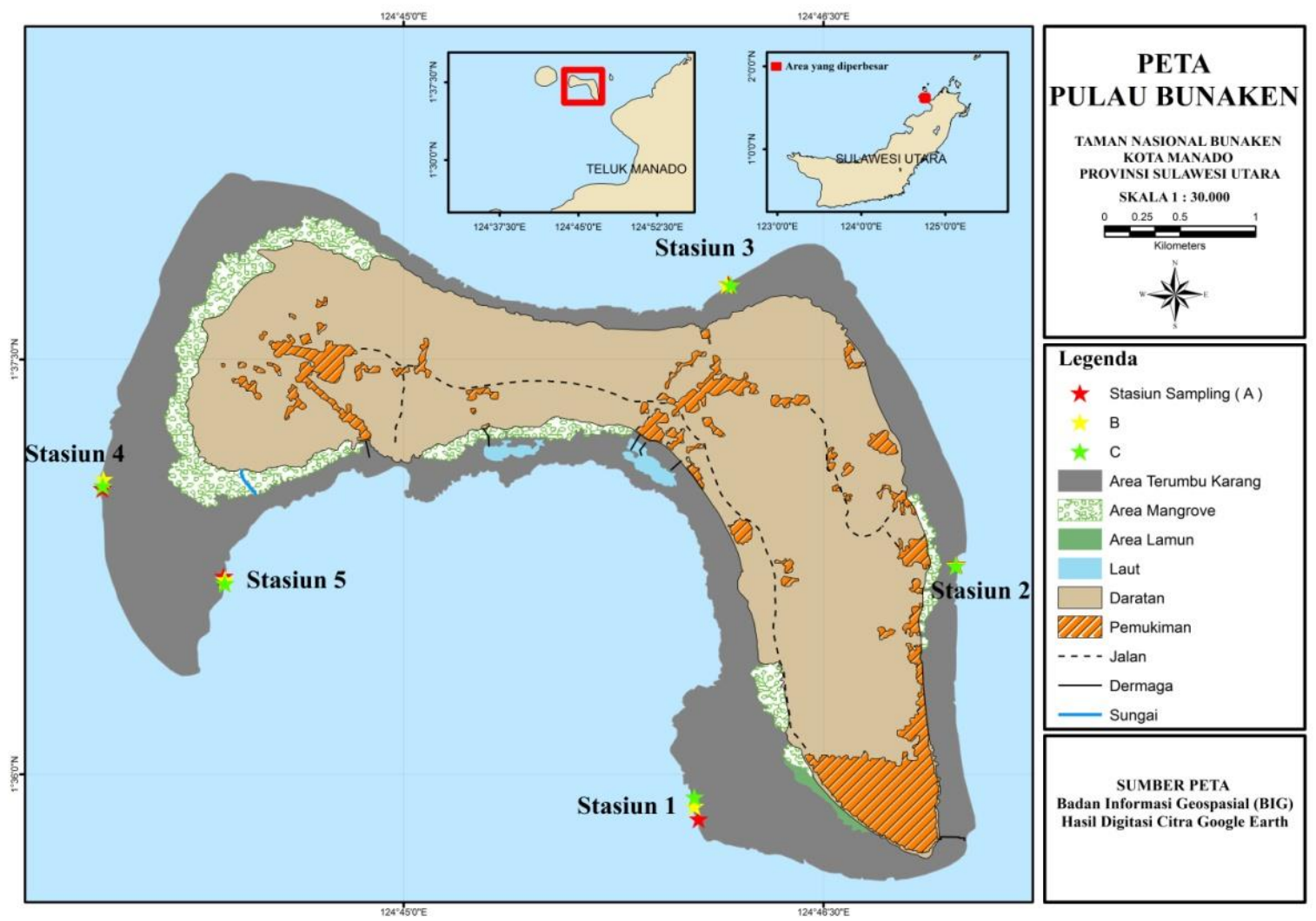

Gambar 1. Lokasi pengambilan sampel.

Preparasi sampel meliputi tahapan pencucian sampel sedimen menggunakan air mengalir di wadah/ayakan sedimen yang berukuran $0.063 \mathrm{~mm}$ kemudian dipindahkan ke wadah untuk di jemur bertujuan untuk pengeringan sampel dan apabila sampel sudah kering diletakkan pada wadah pengamatan (Picking Tray dan Cawan Petri) dengan minimal spesimen yang harus didapati dari 10\% sampel adalah 300 spesimen dari total keseluruhan satu titik sampling. Penjentikan (picking) adalah proses pengambilan individu foraminifera dari partikel sedimen. Identifikasi dilakukan mengacu pada beberapa literatur diantaranya Nobes dan Uthicke (2008), Toruan (2011), Debenay (2012). Proses dokumentasi foraminifera bentik dengan menggunakan mikroskop yang terhubung dengan kamera dan komputer. Pengamatan di bawah mikroskop tipe
Olympus SZx7 yang terhubung dengan kamera Olympus DP21 dan layar monitor.

\section{Analisis Data}

Selanjutnya dilakukan perhitungan FI dengan menggunakan formula dari Hallock dkk., (2003) yaitu FoRAM (Foraminifera dalam Penilaian dan Pemantauan Terumbu, Foraminifera in Reef Assessment and Monitoring) Index adalah metode perhitungan sederhana yang dapat digunakan untuk memantau kondisi lingkungan perairan terumbu karang dengan penghitungan indeks keanekaragaman biota yang berasosiasi dengan terumbu karang termasuk foraminifera bentik:

$$
\mathrm{FI}=(10 \times \mathrm{Ps})+(\mathrm{Po})+(2 \times \mathrm{Ph})
$$

Keterangan :

$\begin{array}{lll}\mathrm{FI} & = & \text { FoRAM Index } \\ \mathrm{Ps} & =\mathrm{Ns} / \mathrm{T}\end{array}$


Ns = Jumlah individu yang mewakili foraminifera yang memiliki simbiosis

Contoh : Amphistegina, Heterostegina, Alveolinella, Borelis, Sorites, Amphisorus, Marginopera.

$\mathrm{Po}=\mathrm{No} / \mathrm{T}$

No = Jumlah individu yang mewakili foraminifera oportunis

Contoh : Ammonia, Elphidium, beberapa marga dari suku Trochaminidae, Litoulidae, Bolvinidae, Buliminidae.

$\mathrm{Ph}=\mathrm{Nh} / \mathrm{T}$

$\mathrm{Nh}=$ Jumlah individu yang mewakili foraminifera kecil lain yang heterotrof

Contoh : Beberapa marga dari Miliolida, Rotalida, Textularia dan lain-lain.

$\mathrm{T}=$ Jumlah seluruh individu foraminifera yang didapatkan dari sampel yang diuji.

Tabel 2. Interpretasi nilai FoRAM Index.

\begin{tabular}{ll}
\hline $\mathrm{FI}>4$ & $\begin{array}{l}\text { Lingkungan sangat } \\
\text { kondusif untuk mendukung } \\
\text { pertumbuhan terumbu } \\
\text { karang } \\
3<\mathrm{FI} \leq 4\end{array}$ \\
& $\begin{array}{l}\text { Lingkungan peralihan } \\
\text { (gambaran awal terjadinya } \\
\text { perubahan lingkungan) }\end{array}$ \\
$2 \leq \mathrm{FI} \leq 3$ & $\begin{array}{l}\text { Lingkungan cukup kondusif } \\
\text { (sedang) untuk } \\
\text { pertumbuhan } \\
\text { karang, namun tidak cukup } \\
\text { untuk pemulihan } \\
\text { Lingkungan tidak layak } \\
\text { untuk pertumbuhan } \\
\text { terumbu karang }\end{array}$ \\
\hline $\mathrm{FI} 2$ &
\end{tabular}

\section{HASIL DAN PEMBAHASAN}

\section{Pendeskripsian dari Genus Foraminifera Bentik}

Dari hasil pengamatan terhadap sampel sedimen permukaan dasar perairan yang telah dilakukan pada 15 titik dalam 5 stasiun tersebar di perairan Pulau Bunaken secara keseluruhan menunjukkan bahwa foraminifera bentik ditemukan dalam setiap sampel sedimen yang diperiksa dengan jumlah bervariasi dari sangat jarang (1 spesimen) hingga banyak (>30 spesimen). Diperoleh 5.770 spesimen foraminifera bentik. Foraminifera bentik yang banyak dan sering ditemukan adalah Amphistegina, merupakan genus yang tersebar cukup merata dan terbanyak di setiap titik lokasi baik di bagian Utara stasiun 3 maupun bagian Selatan stasiun 1. Kedua adalah Calcarina, sejalan dengan yang dikemukakan oleh Boltovkoy dan Wright, (1976), genus ini merupakan salah satu mieobentik yang ditemukan banyak di lingkungan terumbu karang. Genus Textularia ditemukan hampir merata di daerah penelitian dan dalam jumlah dari sedikit (<10 spesimen) hingga jumlah lebih besar (>30 spesimen) dan Millettiana, Reussella, Neocasiidulina merupakan genus dengan jumlah individu yang sangat sedikit. Terdapat 81 spesies foraminifera bentik dari 26 genus. Genus-genus tersebut terdiri dari Ammonia, Amphistegina, Archaias, Calcarina, Clavulina, Cymbaloporetta, Discorbinella, Elphidium, Eponides, Heterostegina, Laticarinina, Miliolinella, Millettiana, Neocasiidulina, Peneroplis, Planorbulina, Pyrgo, Quingueloculina, Reussella, Rosalina, Rotorbis, Sigmamiliolinella, Sorites, Spiroloculina, Textularia, Triloculina. Jumlah individu dari masingmasing genus yang diperoleh disajikan pada Tabel 3. 
Tabel 3. Jumlah individu foraminifera dari masing-masing genus.

\begin{tabular}{|c|c|c|c|c|c|c|c|}
\hline \multirow[t]{2}{*}{ No. } & \multirow[t]{2}{*}{ Genus Foraminifera Bentik } & \multicolumn{5}{|c|}{ Stasiun Sampel } & \multirow{2}{*}{$\begin{array}{l}\text { Jumlah } \\
\text { (individu) }\end{array}$} \\
\hline & & 1 & 2 & 3 & 4 & (in & \\
\hline 1. & Ammonia & 37 & 46 & 0 & 0 & 0 & 83 \\
\hline 2. & Amphistegina & 982 & 534 & 474 & 485 & 475 & 2.950 \\
\hline 3. & Archaias & 0 & 0 & 0 & 20 & 1 & 21 \\
\hline 4. & Calcarina & 12 & 224 & 274 & 155 & 103 & 768 \\
\hline 5. & Clavulina & 1 & 0 & 1 & 2 & 2 & 6 \\
\hline 6. & Cymbaloporetta & 2 & 9 & 1 & 4 & 8 & 24 \\
\hline 7. & Discorbinella & 1 & 0 & 0 & 0 & 4 & 5 \\
\hline 8. & Elphidium & 9 & 72 & 11 & 19 & 4 & 115 \\
\hline 9. & Eponides & 6 & 0 & 17 & 17 & 49 & 89 \\
\hline 10. & Heterostegina & 11 & 49 & 12 & 21 & 52 & 145 \\
\hline 11. & Laticarinina & 0 & 0 & 5 & 0 & 0 & 5 \\
\hline 12. & Miliolinella & 0 & 1 & 1 & 4 & 14 & 20 \\
\hline 13. & Millettiana & 0 & 0 & 0 & 1 & 0 & 1 \\
\hline 14. & Neocasiidulina & 0 & 0 & 0 & 1 & 1 & 2 \\
\hline 15. & Peneroplis & 3 & 53 & 79 & 69 & 11 & 215 \\
\hline 16. & Planorbulina & 1 & 3 & 5 & 11 & 9 & 29 \\
\hline 17. & Pyrgo & 14 & 5 & 22 & 12 & 19 & 72 \\
\hline 18. & Quingueloculina & 16 & 115 & 50 & 72 & 52 & 305 \\
\hline 19. & Reussella & 0 & 2 & 0 & 0 & 0 & 2 \\
\hline 20. & Rosalina & 0 & 3 & 0 & 0 & 2 & 5 \\
\hline 21. & Rotorbis & 2 & 0 & 1 & 0 & 21 & 24 \\
\hline 22. & Sigmamiliolinella & 0 & 0 & 1 & 1 & 1 & 3 \\
\hline 23. & Sorites & 12 & 28 & 121 & 41 & 49 & 251 \\
\hline 24. & Spiroloculina & 8 & 33 & 15 & 39 & 26 & 121 \\
\hline 25. & Textularia & 79 & 54 & 58 & 109 & 122 & 422 \\
\hline \multirow[t]{2}{*}{26.} & Triloculina & 3 & 19 & 5 & 31 & 29 & 87 \\
\hline & TOTAL & 1.199 & 1.250 & 1.153 & 1.114 & 1.054 & 45.770 \\
\hline
\end{tabular}

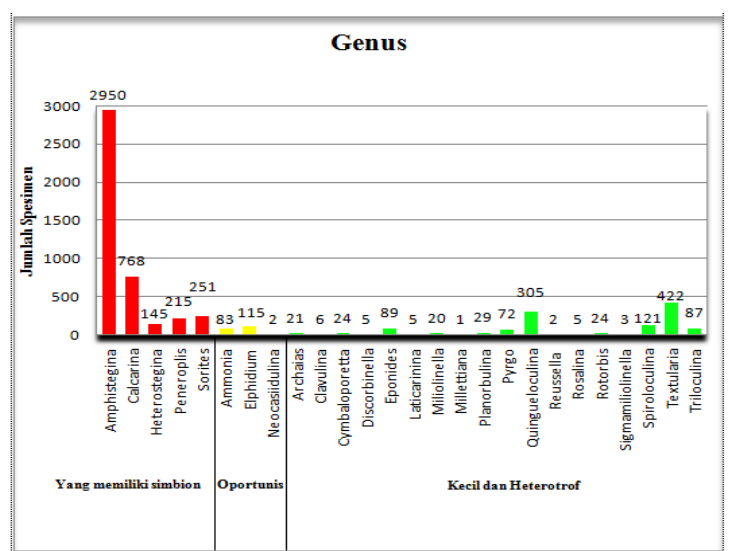

Gambar 2. Diagram jumlah foraminifera bentik berdasarkan genus.

Genus yang terbanyak pada kelompok fungsional yang memiliki simbion adalah Amphistegina dan
Calcarina. Genus yang terbanyak kelompok oportunis adalah Elpidum, sedangkan untuk kelompok kecil dan heterotrof adalah Textularia dan Quingueloculina (Gambar). 


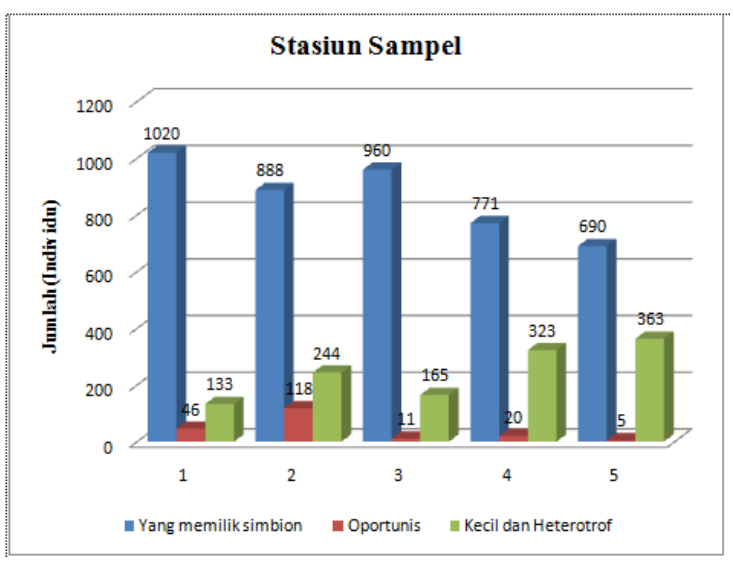

Gambar 3. Perbandingan jumlah individu tiga kelompok fungsional foraminifera bentik.

Selanjutnya jenis foraminifera bentik yang paling banyak ditemukan berasal dari kelompok yang memiliki simbion (Gambar 3). Pada ekosistem terumbu karang yang baik, kelompok Amphistegina akan lebih banyak dari foraminifera lainnya, sedangkan kualitas perairan yang menurun menyebabkan jumlah Amphistegina berkurang (Toruan, 2011) Jumlah yang sedikit dijumpai berasal dari kelompok oportunis dan salah satunya adalah Elphidium dimana genus ini dapat hidup pada daerah oligtrofik dengan intensitas cahaya yang sedang sampai rendah (Troelstra dkk., 1996).

\section{Peta Sebaran Jumlah Individu Menurut Kelompok Fungsional Berdasarkan Genus \\ Peta sebaran foraminifera bentik} menurut kelompok fungsionalnya disajikan dalam bentuk gambar dengan jumlah individu. Penelitian ini dilakukan pada 5 stasiun berbeda yang mewakili 5 kondisi yang berbeda di setiap stasiun dan diharapkan akan representatif dari keadaan foraminifera di perairan Pulau Bunaken. Penentuan kriteria/keterangan yang menyatakan jumlah individu pada masing-masing gambar yang disajikan pada Gambar 4 - Gambar 6.

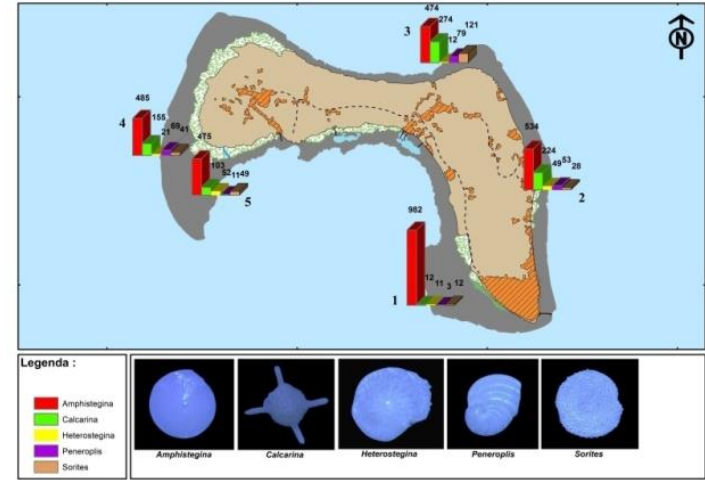

Gambar 4. Peta sebaran kelompok yang memiliki simbion.

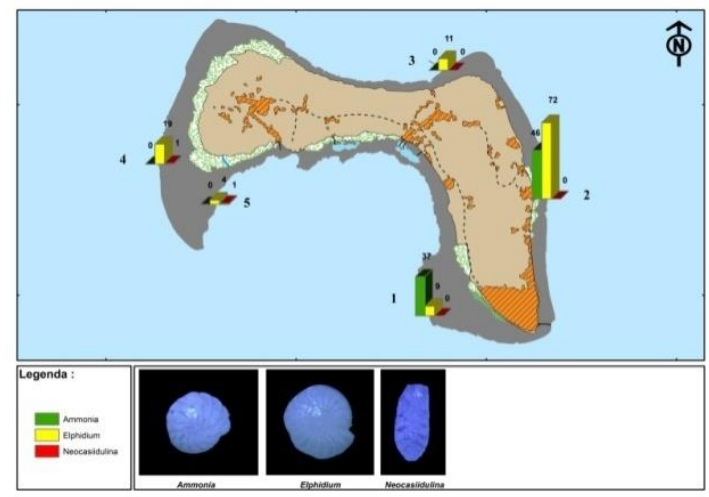

Gambar 5. Peta sebaran kelompok yang oportunis. 


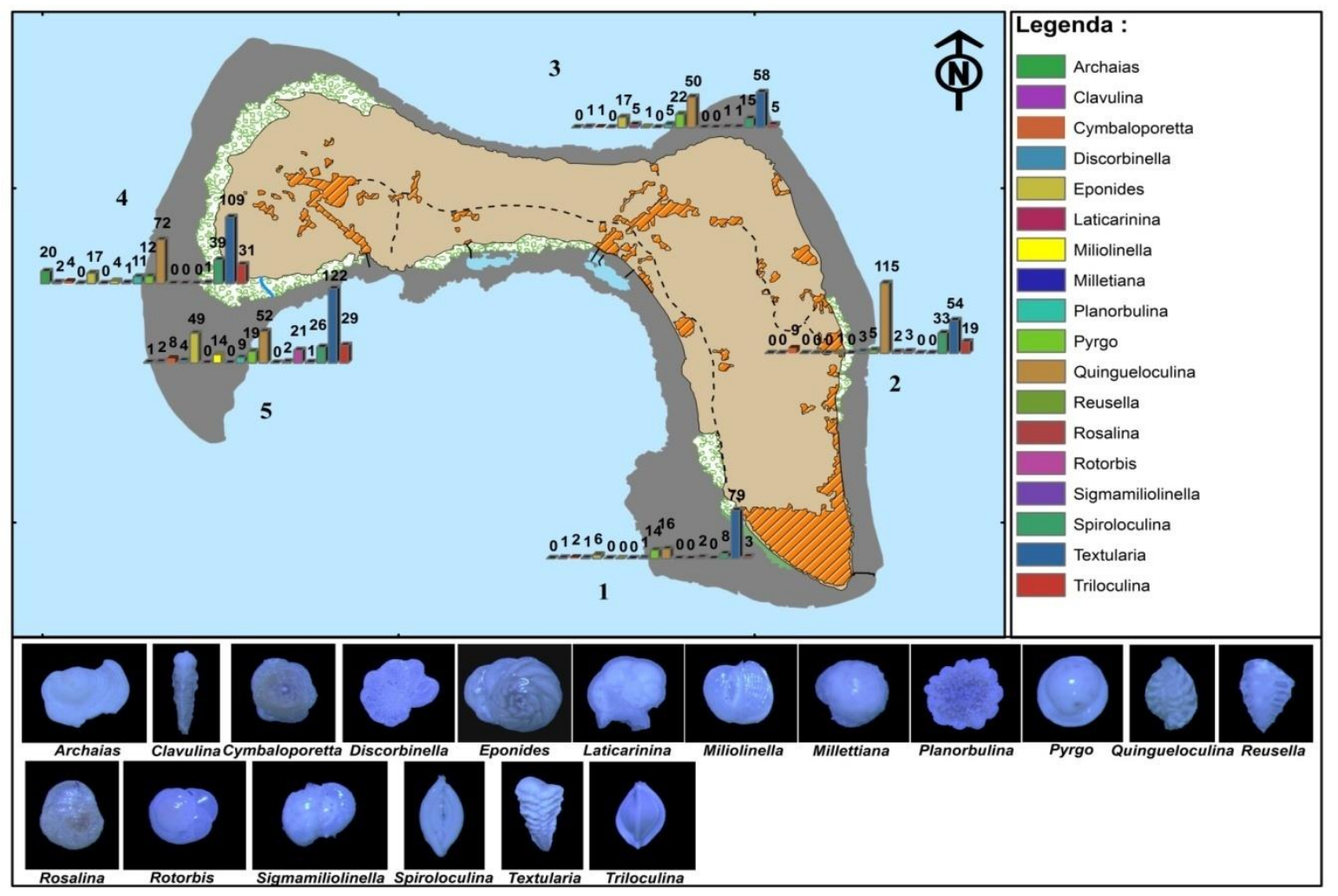

Gambar 6. Peta sebaran kelompok yang kecil dan heterotrof.

\section{FoRAM Index}

Berdasarkan foraminifera bentik yang ditemukan, nilai FoRAM Index (FI) di perairan Pulau Bunaken tergolong tinggi, yaitu berkisar antara 7.18 sampai 10.5 (Gambar 7). Nilai FoRAM Index (FI) yang didapatkan lebih besar dari 4. Nilai ini mengindikasikan bahwa lingkungan perairan terumbu karang di sekitar pulau tersebut ada dalam keadaan masih baik dan sehat. Hallock dkk., (2003) menyatakan bahwa lingkungan suatu perairan yang memiliki nilai FoRAM Index lebih dari empat tergolong sangat kondusif untuk pertumbuhan terumbu karang.

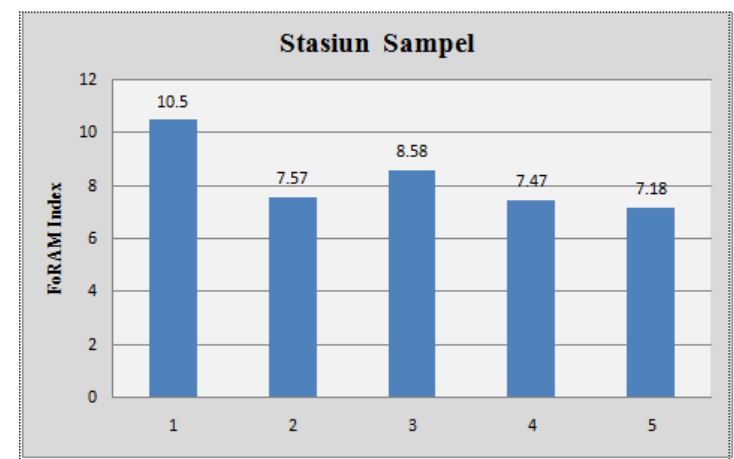

Gambar 7. Nilai FoRAM Index (FI) di setiap stasiun.

\section{KESIMPULAN DAN SARAN}

\section{Kesimpulan}

Berdasarkan hasil penelitian yang dilakukan pada perairan Pulau Bunaken Sulawesi Utara Manado, maka diperoleh simpulan sebagai berikut:

1. Pada perairan Pulau Bunaken yang terdiri dari 15 titik sampling dalam 5 stasiun 
diperoleh 5.770 spesimen foraminifera bentik yang termasuk 81 spesies foraminifera bentik dari 26 genus. Foraminifera bentik yang terbanyak dan sering ditemukan adalah Amphistegina, Calcarina, Textularia dan Millettiana,

Reussella, Neocasiidulina merupakan genus dengan jumlah individu yang sangat sedikit. Genus yang terbanyak pada kelompok fungsional yang memiliki simbion adalah Amphistegina dan Calcarina. Genus yang terbanyak kelompok oportunis adalah Elpidum, sedangkan untuk kelompok kecil dan heterotrof adalah Textularia dan Quingueloculina.

2. Dari pemetaan sebaran jumlah individu foraminifera bentik menurut kelompok fungsionalnya, dimana pada kelompok yang memiliki simbion terdapat 5 genus dan kelompok yang oportunis terdiri dari 3 genus kemudian yang kecil dan heterotrof terdiri dari 18 genus.

3. Berdasarkan perhitungan nilai FoRAM Index (FI) mengindikasikan kondisi perairan Pulau Bunaken, lingkungan sangat kondusif untuk mendukung pertumbuhan terumbu karang. Dengan hasil perhitungan $(\mathrm{FI})$ tergolong tinggi, yaitu berkisar antara 7.18 sampai 10.5 .

\section{Saran}

Berdasarkan penelitian ini maka hal-hal yang dapat disarankan adalah :

1. Perlu adanya penelitian tentang struktur komunitas dan pengukuran parameter fisik perairan yang terkait dengan foraminifera bentik pada perairan Pulau Bunaken.

2. Cangkang foraminifera bentik yang dianalisis sebaiknya cangkang yang masih utuh.

3. Disarankan untuk menggunakan "Rose Bengal' untuk mengetahui apakah foraminifera bentik yang diambil saat penelitian masih hidup atau sudah berupa cangkang mati.

\section{DAFTAR PUSTAKA}

Aulia, K.N., H. Kasmara., T.S. Erawan, dan S.M. Natsir, 2012. Kondisi Perairan Terumbu Karang Dengan Foraminifera Bentik Sebagai Bioindikator Berdasarkan Foram Index Di Kepulauan Banggai, Provinsi Sulawesi Tengah. Jurnal IImu Dan Teknologi Kelautan Tropis. 4(2):335-345.

Boltovskoy, E., dan R. Wraight, 1976. Recent Foraminifera. Dr.W.Jung b.v. Publisher The Hague. 519 hal.

Debenay, J.P., 2012. A Guide to 1.000 Foraminifera from Southwestern Pacific: New Caledonia. Museum National d'Histoire Narurelle Paris. 1-385 hal.

Dewi, K.T., L. Arifin, A. Yuningsih, dan Y. Permanawati, 2012. Meiofauna (Foraminifera) dalam Sedimen dan Keterkaitannya dengan Pantai Pasir Putih Senggigi serta Kondisi Perairan Lombok Barat. Jurnal IImu dan Teknologi Kelautan Tropis. 4(1):47-54.

Dewi, K.T., S.M. Natsir, dan Y. Siswantoro, 2010. Mikrofauna (Foraminifera) Terumbu Karang Sebagai Indikator Perairan Sekitar Pulau-Pulau Kecil. Jurnal IImu dan Teknologi Kelautan Tropis 1. Edisi khusus:162-170 hal.

Gustiani, L., dan D. llahude, 2012.

Foraminifera Bentik Dalam Sedimen Sebagai Indikator Kondisi Lingkungan Terumbu Karang Di Perairan Pulau Cemara Besar dan Kecil Kepulauan Karimunjawa Jawa Tengah. Jurnal Geologi Kelautan 10(1):23-36. 
Hallock, P., B.H. Lidz, E.M.C. Burkhhard, dan K.B. Donnelly, 2003. Foraminifera as Bioindikators in Coral Reef Assessment and Monitoring: The FoRAM Index Environmental Monitoring and Assessment. 81:221-238.

Natsir, S.M., 2010. Foraminifera Bentik sebagai Indikator Kondisi Lingkungan Terumbu Karang Perairan Pulau Katok Besar dan Pulau Nirwana, Kepulauan Seribu. Jurnal Oseanologi dan Limnologi di Indonesia. 36(2):181-192.

Nobes, K., dan S. Uthicke, 2008. Benthic Foraminifera of The Great Barrier Reef. A Guide To Species Potentially Useful As Water Quality Indicators. Marine and Tropical Sciences Research Facility, Australian Institute of Marine Science, Townsville. 48 hal.

Rositasari, R., 2011. Karakteristik Komunitas Foraminifera di Perairan Teluk Jakarta. Jurnal IImu dan Teknologi Kelautan Tropis. FPIK IPB. 3(2):100-111.

Setiawan, F., J.D. Kusen, dan G.J.F. Kaligis, 2013. Perubahan Struktur Komunitas Karang di Taman Nasional Bunaken, Sulawesi Utara. Aquatic Science \& Management. Pascasarjana, Universitas Sam Ratulangi. 1(2):117-123.

Toruan, L.N.L., 2011. Pendugaan Kualitas Ekosistem Terumbu Karang Di Kepulauan Seribu Dengan Menggunakan Proporsi Foraminifera Bentik Sebagai Bioindikator. Tesis Magister Sains Program Studi IImu Kelautan IPB Bogor. 134 hal.

Troelstra, S.R., H.M. Jonkers, S. de Rijk, 1996. Larger foraminifera from the Spermonde Archipelago (Sulawesi, Indonesia). Scripta Geologi. 113:93-120. 